\title{
IDENTIFICAÇÃO E QUANTIFICAÇÃO DE VOLÁTEIS DE CAFÉ ATRAVÉS DE CROMATOGRAFIA GASOSA DE ALTA RESOLUÇÃO / ESPECTROMETRIA DE MASSAS EMPREGANDO UM AMOSTRADOR AUTOMÁTICO DE "HEADSPACE"1
}

\author{
Leonardo César AMSTALDEN ${ }^{2},{ }^{\star}$, Flávio LEITE², Hilary Castle de MENEZES ${ }^{3}$
}

\begin{abstract}
RESUMO
Usando um amostrador automático, os "headspaces" de três marcas comerciais de café torrado e moído foram analisados qualitativa e quantitativamente quanto a composição dos voláteis responsáveis pelo aroma através da técnica de cromatografia gasosa/espectrometria de massas. Uma vez que a metodologia não envolveu isolamento ou concentração dos aromas, suas proporções naturais foram mantidas, além de simplificar o preparo das amostras. O emprego do amostrador automático permitiu também boa resolução dos picos cromatográficos sem o emprego de criogenia, contribuindo para redução no tempo de análise. Noventa e um componentes puderam ser identificados, sendo que alguns compostos conhecidos como presentes em café como o dimetilsulfeto, metional e furfuril mercaptana não foram detectados. Os voláteis presentes em maior concentração puderam ser quantificados com o auxílio de dois padrões internos. A técnica se provou viável, tanto para caracterização como para quantificação de voláteis de café.
\end{abstract}

Palavras-chave: café; voláteis; "headspace"; identificação; quantificação

\section{SUMMARY}

IDENTIFICATION AND QUANTIFICATION OF COFFEE VOLATILE COMPONENTS THROUGH HIGH RESOLUTION GAS CHROMATOGHAPH/MASS SPECTROMETER USING A HEADSPACE AUTOMATIC SAMPLER. Employing an automatic headspace sampler, the headspaces of three commercial brands of ground roasted coffee were qualitatively and quantitatively analyzed by gas chromatography / mass spectrometry. Since the methodology did not involve aroma isolation or concentration, their natural proportions were maintained, providing a more accurate composition of the flavors, and simplifying sample preparation. The automatic sampler allowed good resolution of the chromatographic peaks without cryofocusing the samples at the head of the column during injection, reducing analysis time. Ninety one compounds were identified and some known coffee volatiles, such as dimethyl sulphide, methional and furfuryl mercaptan were not detected. The more concentrated volatiles could be identified using two internal standards. The technique proved viable, for both characterization and for quantification of coffee volatiles.

Keywords: coffee; volatiles; headspace; identification; quantification

\section{1 - INTRODUÇÃO}

O Brasil não é apenas um grande produtor, mas um grande consumidor de café. De acordo com a ava-

\footnotetext{
${ }_{1}^{1}$ Recebido para publicação em 06/02/01. Aceito para publicação em 21/05/01.

${ }^{2}$ Inst. Ciências Biológicas e Química -PUC-Campinas - Av. John Boyd Dunlop s/n - C.P. 1111 CEP 13020-904- Campinas SP

${ }^{3}$ Depto. Tecnologia de Alimentos, Faculdade de Engenharia de Alimentos, UNICAMP, C.P. 6121-CEP 13081-970-Campinas.

${ }^{*}$ A quem a correspondência deve ser enviada.
}

liação de RAMOS [10], o consumo interno brasileiro equipara-se à soma das exportações para os Estados Unidos, Alemanha, Itália, Japão e França, entretanto a qualidade do produto comercializado internamente não é normatizada. O selo de pureza instituído pela $A B I C$ (Associação Brasileira da Indústria de Café) garante o café com até $1 \%$ de impurezas, previstas de acordo com a legislação, porém não há um controle efetivo sobre a qualidade da bebida resultante.

A qualidade da bebida café, caracterizada por seu sabor e aroma, é influenciada por diversos fatores pré e pós-colheita que garantem a expressão final da qualidade do produto [3]. Dentre os fatores pré-colheita são destacados a espécie e variedades de café, o local de cultivo, a maturação dos grãos, a incidência de microrganismos e o efeito de adubações. Em relação aos fatores pós-colheita destacam-se as fermentações enzimáticas e microbianas, os processos de armazenamento do café beneficiado, as misturas (blending) e a torração dos grãos.

BÁRTHOLO e GUIMARÃES [1] salientam as diferenças na colheita e processamento: a colheita do café do Brasil é feita por derriça onde é colhida uma mistura de frutos de diferentes características com relação à maturação, cor, densidade e teor de umidade, para depois serem processados por via seca (o fruto é seco com casca). O café Colombiano e de outros países da América Central e África é colhido "a dedo", ou seja, só os grãos maduros, que depois são processados por via úmida (grãos despolpados). Estes apresentam uma bebida suave, diferenciada da brasileira.

A etapa de torração é a exposição dos grãos verdes ao ar aquecido num processo rápido, o suficiente para liberar a água livre e ligada. Os grãos secos são aquecidos a mais de $200^{\circ} \mathrm{C}$. Ao redor dessa temperatura ocorrem reações de pirólise nos grãos, onde se desenvolvem a cor, e os compostos que contribuem para o aroma e sabor de café [13].

Devido a grande importância que o aroma representa na qualidade e aceitação do café, seus voláteis têm sido objeto de muitas pesquisas, sendo que centenas de compostos funcionais já foram identificados, como aldeídos, cetonas, ésteres, mercaptanas, sulfetos, dissulfetos, tiofenos e tiazóis [12].

Muitos compostos voláteis foram isolados por várias técnicas como: extração por solventes seguido de análise cromatográfica [2, 7, 11] e "purge and trap" [6, 16].

Outras técnicas descritas na literatura, como o emprego de polímeros porosos (Tenax GC) para cole- 
tar e concentrar os voláteis (adsorção), para posterior desorção e análise cromatográfica, são úteis quando se procura identificar componentes presentes em quantidades muito pequenas [8, 9, 14].

Entretanto, todos estes métodos podem levar a mudanças na composição: a extração por solventes é limitada aos compostos com ponto de ebulição mais alto que o do solvente usado; na extração por polímeros as proporções dos voláteis podem se alterar, dependendo da sua capacidade de adsorção/desorção no polímero, afetando a análise quantitativa.

De acordo com SHIMODA e SHIBAMOTO [12], a injeção direta do "headspace" de uma amostra do produto na coluna de um cromatógrafo gasoso fornece a melhor composição dos aromas. Para contornar o problema do alargamento dos picos que ocorre quando uma grande amostra do "headspace" é injetada, o autor recorre à técnica de reter a amostra criogenicamente na cabeça da coluna, durante a injeção, com nitrogênio líquido (cryofocus).

Com o advento de amostradores automáticos de "headspace", esta técnica analítica teve um grande avanço em relação à injeção manual das amostras, tanto em relação à detectabilidade dos compostos, como na repetibilidade das análises e sua praticidade como método de rotina.

Esta pesquisa teve por objetivos identificar e quantificar a composição dos principais voláteis de amostras de café torrado e moído comercializado no Brasil, através da técnica de cromatografia gasosa de alta resolução aliada à espectrometria de massas, empregando um amostrador automático de "headspace". Foi verificada também a viabilidade desta metodologia para controle de qualidade de amostras de café.

\section{2 - Materiais e Métodos}

\section{1 - Materiais}

Amostras de café (Coffea arabica) torrado e moído foram compradas diretamente de torrefações na região de Campinas - SP:

- Café A1 - torração normal; embalagens tipo "almofada" metalizadas (polipropileno biorientado metalizado).

- $\quad$ Café A2 - torração normal; embalagens a vácuo.

- Café B - torração normal; embalagens tipo "almofada" metalizadas (polipropileno biorientado metalizado).

- $\quad$ Café C - torração extra-forte; embalagens tipo almofada (polipropileno perolado).

Observação: Para se obter a máxima concentração de voláteis de cada amostra, estas foram analisadas no mesmo dia do empacotamento.

Padrões cromatográficos de compostos presentes em aroma de café, descritos na literatura, foram adquiridos da Aldrich Chemical Company Inc.

\section{2 - Preparo das amostras}

Quatro gramas de café torrado e moído foram colocados em frascos de "headspace" PRO92010, sendo a massa da amostra pesada em balança analítica. $\mathrm{Pa}$ drões internos, tiofeno e furfuril mercaptana, foram adicionados em $1 \mathrm{~mL}$ a cada frasco para as análises quantitativas. Após cada adição, a massa da amostra era novamente anotada e os frascos lacrados.

\section{3 - Parâmetros do "headspace"}

Foi utilizado um amostrador automático (headspace sampler) modelo HP 7694E, sendo que as condições de operação foram otimizadas de acordo com a metodologia proposta pelo fabricante [5] para obter a meIhor resposta cromatográfica da amostra. As condições de operação foram as seguintes: temperatura do frasco $70^{\circ} \mathrm{C}$; tempo de equilíbrio $20 \mathrm{~min}$; temperatura do "loop" $150^{\circ} \mathrm{C}$; temperatura da "transfer line" $170^{\circ} \mathrm{C}$; tempo de enchimento do "loop" $2 \mathrm{~s}$; tempo de equilíbrio no "loop" $15 \mathrm{~s}$; tempo de injeção $1 \mathrm{~min}$; agitação baixa; pressurização do frasco 22psi.

\section{4 - Cromatografia gasosa}

Foi utilizado um cromatógrafo gasoso marca HP modelo 6890+ com injetor split/splitless, coluna capilar - "HP Wax Bonded Polyetylene Glycol" - 60m (comprimento) x 250mm (diâmetro interno) x 0,50mm (espessura do filme) nominal; detector FID (detector de ionização por chama). Como proposto por SHIMODA e SHIBAMOTO [12], o cromatógrafo gasoso era equipado com um acessório que possibilita o resfriamento da amostra na cabeça da coluna com nitrogênio líquido. Porém, durante o desenvolvimento da metodologia analítica, foi observado que, nas condições empregadas, havia boa separação dos compostos sem alargamento dos picos, mesmo sem o emprego de criogenia.

O injetor operou no modo splitless com temperatura do bloco de $180^{\circ} \mathrm{C}$. O forno estava programado para uma temperatura inicial de $35^{\circ} \mathrm{C}$ mantendo por 1 minuto; depois $3^{\circ} \mathrm{C} / \mathrm{min}$. até $100^{\circ} \mathrm{C}$ e $5^{\circ} \mathrm{C} / \mathrm{min}$. até $160^{\circ} \mathrm{C}$, mantendo por 10 minutos. A temperatura do detector foi de $180^{\circ} \mathrm{C}$ e o gás de arraste $\mathrm{N}_{2}$, mantido ao fluxo constante de $1 \mathrm{~mL} / \mathrm{min}$.

\section{5 - Cromatografia gasosa / Espectrometria de massas}

O processo de identificação utilizado foi, após a separação por cromatografia gasosa de alta resolução com a mesma coluna capilar "HP Wax Bonded Polyetylene Glycol" - 60m (comprimento) x 250mm (diâmetro interno) $\times 0,50 \mathrm{~mm}$ (espessura do filme) nominal, o acoplamento a um detector de massas. O equipamento utilizado foi: HP Mass Selective Detector 5971 Series da Hewlet Packard. Energia de Ionização: 70eV.

\section{6 - Análise quantitativa}

A quantificação dos voláteis do espaço livre foi conduzida utilizando curvas de calibração para os com- 
postos de que se dispunha padrões. Matrizes de café "branco" foram preparadas para fornecer um pó isento de voláteis nas temperaturas de ensaio. Foi observado que, para melhores resultados como branco, deve-se deixar o pó em estufa entre $80^{\circ}$ e $100^{\circ} \mathrm{C}$ por 48 horas.

A três amostras, contendo $4 \mathrm{~g}$ de pó de café "branco", foram adicionadas quantidades conhecidas de cada padrão, com o auxílio de uma micro-seringa (as quantidades foram sucessivamente crescentes do frasco 1 ao 3). Com isso, obteve-se em cada frasco uma mistura de concentrações conhecidas de todos os padrões disponíveis. Os "headspaces" das amostras foram injetados no cromatógrafo.
Foram construídas curvas de calibração dos padrões, usadas para as análises quantitativas. Os cálculos foram realizados pelo software da HP-Chemstation. A resposta do detector a todos os compostos foi linear com variação $£$ a $2 \%$.

\section{3 - RESULTADOS E DISCUSSÃO}

\section{1 - Análise Qualitativa}

Um cromatograma obtido com as condições experimentais reportadas está na Figura 1. Para melhor visualização os picos foram numerados e identificados na Tabela 1.

TABELA 1. Composição química do aroma do "headspace" das amostras de café

\begin{tabular}{|c|c|c|c|c|c|c|c|c|c|}
\hline $\begin{array}{l}\text { Pico na } \\
\text { fig. } 1 \\
\end{array}$ & Composto & $\begin{array}{c}\text { Área } \\
(\%)\end{array}$ & $\mathrm{DPR}^{\mathrm{a}}$ & $\begin{array}{c}\text { Identificado } \\
\text { via }^{\text {b }} \\
\end{array}$ & $\begin{array}{c}\text { Pico na } \\
\text { fig. } 1 \\
\end{array}$ & Composto & $\begin{array}{c}\text { Área } \\
(\%)\end{array}$ & $\mathrm{DPR}^{\mathrm{a}}$ & $\begin{array}{c}\text { Identificado } \\
\text { via }^{\text {b }} \\
\end{array}$ \\
\hline 1 & Buteno & 0.09 & 3.54 & EM & 51 & 2-Pentil furano & 0.12 & 9.22 & EM \\
\hline 2 & Metanetiol & 0.07 & 8.18 & EM & 52 & 2-Metoxi-metil furano & 0.15 & 14.25 & EM \\
\hline 3 & Acetaldeído & 1.82 & 4.08 & EM, TR & 53 & 3-Metil-3-buteno-1-ol & 0.06 & 16.50 & EM \\
\hline 4 & Formiato de metila & 0.45 & 1.44 & EM,TR & 54 & Tiazol & 0.03 & 17.10 & EM \\
\hline 5 & Furano & 1.20 & 2.77 & EM,TR & 55 & Estireno & 0.04 & 16.55 & EM \\
\hline 6 & Metil ciclobutil éter & 0.03 & 8.49 & EM & 56 & Dihidro-2-metil-3 furanona & 1.10 & 4.69 & EM \\
\hline 7 & 2-Metil propanal & 1.24 & 0.52 & EM, TR & 57 & Metil pirazina & 2.23 & 2.14 & EM \\
\hline 8 & Acetona & 5.38 & 4.94 & EM, TR & 58 & Amino piridina & 0.03 & 10.14 & EM \\
\hline 9 & Acetato de metila & 1.39 & 3.46 & EM, TR & 59 & 4-Metil tiazol & 0.05 & 7.94 & EM \\
\hline 10 & 2-Metil furano & 3.19 & 3.22 & EM, TR & 60 & 3-Hidroxi 2-butanona & 0.64 & 5.21 & EM \\
\hline 11 & Butanal & 0.14 & 18.15 & EM & 61 & 1-Hidroxi-2-propanona & 1.18 & 6.23 & EM \\
\hline 12 & Acetato de etila & 0.14 & 13.62 & EM & 62 & 2-Heptanol & 0.09 & 16.42 & EM \\
\hline 13 & 2-Butanona & 8.12 & 2.90 & EM, TR & 63 & n.i. & 0.36 & 9.13 & \\
\hline 14 & 2-Metil butanal & 2.84 & 6.23 & EM & 64 & 2,5-Dimetil pirazina & 0.27 & 8.67 & EM \\
\hline 15 & 3-Metil butanal & 1.50 & 5.22 & EM & 65 & 2,6-Dimetil pirazina & 0.52 & 13.32 & EM \\
\hline 16 & Etanol & 1.19 & 1.18 & EM, TR & 66 & Etil pirazina & 0.17 & 13.31 & EM \\
\hline 17 & 3,4-Dihidropirano & 0.67 & 17.21 & EM & 67 & 3-Hidroxi-2-pentanona & 0.14 & 26.64 & EM \\
\hline 18 & 2,5-Dimetilfurano & 0.39 & 3.10 & EM, TR & 68 & 2,3-Dimetil pirazina & 0.15 & 10.19 & EM \\
\hline 19 & 1-Propinil ciclopropanol & 0.06 & 16.54 & EM & 69 & 2,3-Butanediol & 0.14 & 15.78 & EM \\
\hline 20 & 2,3 Butanodiona & 1.15 & 1.11 & EM, TR & 70 & 3-Penteno-2-ol & 0.11 & 11.07 & EM \\
\hline 21 & Pentanona & 0.41 & 6.99 & EM & 71 & 1-Hidroxi 2-butanona & 0.29 & 3.12 & EM \\
\hline 22 & 4-Etenilciclohexeno & 0.04 & 14.37 & EM & 72 & 2-Etil-6-metil-pirazina & 0.17 & 3.95 & EM \\
\hline 23 & Acetonitrila & 0.06 & 15.35 & EM & 73 & Trimetil pirazina & 0.15 & 11.53 & EM \\
\hline 24 & $\begin{array}{l}\text { Ácido butanoico, 3-metil } \\
\text { éster }\end{array}$ & 0.06 & 11.03 & EM & 74 & 1-Metoxi-2-butanol & 0.05 & 41.86 & EM \\
\hline 25 & Tiofeno $(\mathrm{PI})^{\mathrm{c}}$ & 10.40 & 2.74 & EM, TR & 75 & 2-Etoxi propanol & 0.07 & 31.24 & EM \\
\hline 26 & 4-Heptanona & 0.21 & 13.03 & EM & 76 & Furanometanetiol & 0.04 & 41.49 & EM \\
\hline 27 & 1,3,5-Cicloheptatrieno & 0.17 & 18.46 & EM & 77 & Furfuril mercaptana $(\mathrm{PI})^{\mathrm{c}}$ & 18.33 & 4.52 & \\
\hline 28 & 2,5-Dimetil, 2,4 hexadieno & 0.11 & 14.75 & EM & 78 & Ácido acético & 2.28 & 2.18 & EM \\
\hline 29 & 3-Hexanona & 0.07 & 12.52 & EM & 79 & 1-Acetiloxi 2-propanona & 0.94 & 3.53 & EM \\
\hline 30 & 2,3 Pentanodiona & 1.28 & 0.59 & EM, TR & 80 & 2-Furancarboxialdeido & 0.60 & 7.48 & EM \\
\hline 31 & n.i. & 0.05 & 15.85 & & 81 & Formiato de furfurila & 0.07 & 22.02 & EM \\
\hline 32 & Fenol & 0.17 & 5.42 & EM & 82 & 2-Etenil-6-metil-pirazina & 0.22 & 23.21 & EM \\
\hline 33 & Dimetil dissulfeto & 0.07 & 16.59 & EM & 83 & Pirrol & 0.54 & 9.33 & EM \\
\hline 34 & Hexanal & 0.08 & 16.91 & EM & 84 & 2-Metoxi-metil furano & 0.23 & 6.95 & EM \\
\hline 35 & 2-Metil propanol & 0.13 & 10.81 & EM & 85 & 3,3-Dimetil-2-butanol & 0.14 & 15.72 & EM \\
\hline 36 & 3-Metil tiofeno & 0.15 & 11.99 & EM & 86 & Acetato furfurílico & 0.12 & 18.21 & EM \\
\hline 37 & 2-Metil 2-butenal & 0.08 & 14.59 & EM & 87 & Ácido propanóico & 0.90 & 6.74 & EM \\
\hline 38 & 2-propen-1-ol & 0.09 & 14.12 & EM & 88 & $\begin{array}{l}\text { Dihidro-2H-tiopirano- } \\
3(4 \mathrm{H}) \text {-ona }\end{array}$ & 0.14 & 16.99 & EM \\
\hline 39 & 2-Pentanol & 0.08 & 14.68 & EM & 89 & 2,3-Butanediol & 0.39 & 13.19 & EM \\
\hline 40 & 2,4-Dimetil-3-pentanona & 0.13 & 4.79 & EM & 90 & $\begin{array}{l}\text { 2-Furanometanol, } \\
\text { propanoato }\end{array}$ & 0.11 & 9.53 & EM \\
\hline 41 & 1-Metoxi-2-propanol & 0.08 & 14.43 & EM & 91 & $\begin{array}{l}\text { 1-Metil-2-pirrol } \\
\text { carboxialdeido }\end{array}$ & 0.27 & 11.52 & EM \\
\hline 42 & 2,2-Dimetil pentanona & 0.08 & 11.94 & EM & 92 & $\begin{array}{l}\text { 5-Metil-2- } \\
\text { furanocarboxialdeido }\end{array}$ & 0.12 & 17.50 & EM \\
\hline 43 & 1-Metil pirrol & 1.04 & 5.92 & EM & 93 & n.i. & 0.19 & 11.40 & \\
\hline 44 & 3-Metil fenol & 0.25 & 5.77 & EM & 94 & $\begin{array}{l}3,6,9,12- \\
\text { Tetraoxahexadecanol }\end{array}$ & 0.10 & 19.64 & EM \\
\hline 45 & $\begin{array}{l}5,6 \quad \text { Dihidro- } 4 \mathrm{H}- \\
\text { ciclopentafurano }\end{array}$ & 0.10 & 13.77 & EM & 95 & n.i. & 0.16 & 16.31 & \\
\hline 46 & 1-Etil pirrol & 0.12 & 19.02 & EM & 96 & n.i. & 0.29 & 18.80 & \\
\hline 47 & Piridina & 11.22 & 0.43 & EM, TR & 97 & n.i. & 0.11 & 29.05 & \\
\hline 48 & 3-Metil-1-butanol & 0.14 & 3.51 & EM & 98 & Álcool furfurílico & 5.02 & 13.31 & EM, TR \\
\hline 49 & 2,5 Dimetil 1H-pirrol & 0.11 & 21.00 & EM & 99 & Butirolactona & 1.59 & 18.62 & EM \\
\hline 50 & Pirazina & 0.78 & 4.03 & EM, TR & & & & & \\
\hline
\end{tabular}

a Desvio-padrão relativo (DP/média $\times 100)$ de três injeçõe 
O cromatograma apresentado na Figura 1 é representativo de todas as amostras estudadas, uma vez que as diferenças encontradas entre uma amostra e outra foram apenas quantitativas. Outros aromas possivelmente presentes, não aparecem em concentrações suficientes para sensibilizar o detector. Apesar da técnica não empregar o isolamento e enriquecimento dos voláteis, obteve-se boa resolução dos picos dos compostos presentes em maior concentração e que são os principais contribuintes na formação da impressão sensorial de café torrado. Além disso, como essa separação foi obtida sem o emprego do resfriamento criogênico dos compostos na cabeça da coluna (cryofocussing), o tempo de análise foi reduzido e operacionalmente simplificado.

Os voláteis responsáveis pelo aroma do café são formados durante a torração e ficam retidos na estrutura celular do grão torrado. Os aldeídos e cetonas são provenientes da decomposição de carboidratos durante o aquecimento e compreendem cerca de $0,04 \%$ do café torrado. Pequenos teores de sulfetos, oriundos das proteínas são importantes no aroma do café [13].

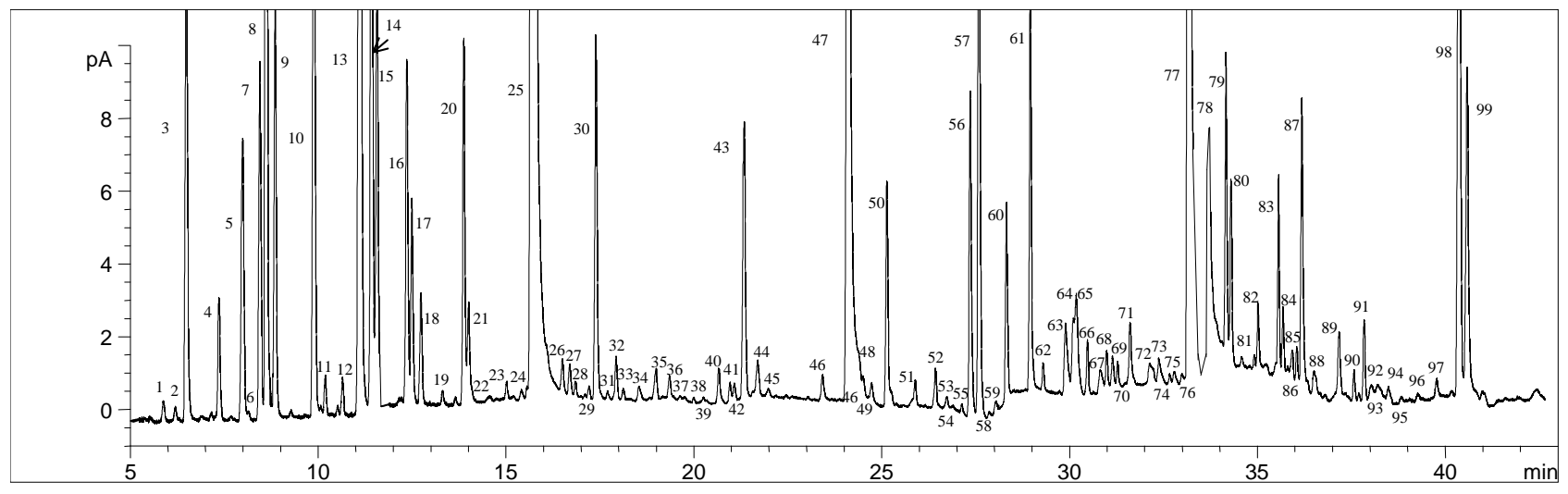

FIGURA 1. Cromatograma típico do "headspace" das amostras de café

A degradação de Strecker leva à formação de vários compostos reportados como importantes na formação do aroma, tais como 2-metil e o 3-metilbutanal (compostos 14 e 15), que são perceptíveis sensorialmente mesmo em altas diluições [7]. Metanetiol (composto 2), que individualmente tem aroma fortemente pútrido, é produto da degradação térmica do metional, não encontrado neste estudo, embora reportado como presente em técnicas de "headspace" [6].

Outros compostos sulfurados como o dimetilsulfeto e furfuril mercaptana não foram encontrados. Cafés cultivados em grandes altitudes liberam e retém grandes quantidades de dimetilsulfeto que é um importante constituinte do aroma e sabor de cafés de alta qualidade [13]. Vale ressaltar que, TRESSI e SILWAR [15] identificaram 23 compostos sulfurados presentes até ao nível de traços em cafés Arábica colombianos, e não encontraram o dimetil sulfeto, e sim dimetil-dissulfeto, dimetiltrissulfeto e metil-etil-trissulfeto. Neste trabalho foi caracterizado o dimetil-dissulfeto (composto 33 ). Os autores também sugerem que a furfuril mercaptana e a 5-metilfurfuril mercaptana são parcialmente responsáveis por mudanças que ocorrem no aroma de café armazenado, sendo encontradas em concentrações de $1100 p p b$ em cafés Arábica com dez dias após a torração. Devido ao impacto negativo que estes dois compostos representam no aroma de café, sua presença foi exaustivamente pesquisada nos pós em estudo, tanto em pós recém-torrados, como até 90 dias após a torração, porém não foram encontradas quantidades detectáveis. SHIMODA e SHIBAMOTO [12] também não encontraram furfuril mercaptana em sua pesquisa. Desta forma, uma vez que se dispunha de padrões, a furfuril mercaptana passou a ser acrescentada aos pós, por seu tempo de retenção conveniente, como um dos padrões internos para a análise quantitativa. Analogamente, o tiofeno que tem detecção por espectrometria de massas, dentre os detectores utilizados, também foi escoIhido como padrão interno.

Muitas pirazinas resultantes de reações de Maillard foram identificadas em café torrado, mas apenas algumas apresentam contribuição para o aroma [4].

Outros voláteis sensorialmente importantes são as a-dicarbonilas 2,3-butanodiona e 2,3-pentanodiona (compostos 20 e 30) que apresentam um aroma amanteigado.

\section{2 - Análise quantitativa}

Como a metodologia aplicada não envolveu a concentração dos voláteis, a maioria dos compostos identificados estava presente em quantidades muito pequenas, dificultando a integração dos picos. A reprodutibilidade do método foi medida e reportada pelo desvio padrão relativo (Tabela 1), [12]. Os compostos leves e presentes em maior concentração tiveram valores aceitáveis para técnicas de "headspace" (até aproximadamente $5 \%$ ). Compostos com pequenas áreas dos picos ou menos voláteis, como por exemplo o álcool furfurílico, apresentaram valores muito altos (acima de 10\%), uma vez que podem ficar condensados ou adsorvidos nas superfícies do sistema, necessitando de outras condições analíticas para sua quantificação. Para análise quantitativa foram então escolhidos compostos mais 
concentrados ou reportadamente importantes na constituição do aroma de café e que tiveram boa reprodutibilidade no método empregado (compostos $n^{\circ}$ $3,4,5,7,8,9,10,13,14,15,16,18,20,30,47$ e 50). Cada amostra foi analisada em triplicata e as concentrações dos compostos calibrados estão na Tabela 2.

TABELA 2. Concentração dos componentes do "headspace" de amostras de café

\begin{tabular}{lcccccccc}
\hline \multicolumn{10}{c}{ Café A1 } & \multicolumn{2}{c}{ Café A2 } & \multicolumn{2}{c}{ Café B } & \multicolumn{2}{c}{ Café C } \\
\hline Composto & $\overline{\mathrm{C}}(\mathrm{mg} / \mathrm{kg})$ & $\mathrm{DP}^{\mathrm{a}}$ & $\overline{\mathrm{C}}(\mathrm{mg} / \mathrm{kg})$ & $\mathrm{DP}^{\mathrm{a}}$ & $\overline{\mathrm{C}}(\mathrm{mg} / \mathrm{kg})$ & $\mathrm{DP}^{\mathrm{a}}$ & $\overline{\mathrm{C}}(\mathrm{mg} / \mathrm{kg})$ & $\mathrm{DP}^{\mathrm{a}}$ \\
\hline \hline Acetaldeido & 3,89 & 0,13 & 2,47 & 0,18 & 7,39 & 0,11 & 3,71 & 0,67 \\
Formiato de metila & 1,64 & 0,03 & 1,10 & 0,09 & 2,22 & 0,027 & 1,01 & 0,23 \\
Furano & 1,26 & 0,01 & 0,880 & 0,75 & 3,31 & 0,01 & 0,966 & 0,154 \\
2-metil propanal & 3,15 & 0,39 & 1,43 & 0,02 & 2,52 & 0,06 & 2,72 & 0,23 \\
Acetona & 11,54 & 0,078 & 6,82 & 0,096 & 14,48 & 0,13 & 10,86 & 0,43 \\
Acetato de metila & 4,71 & 0,15 & 2,59 & 0,68 & 5,99 & 0,03 & 4,61 & 0,14 \\
Metil furano & 7,43 & 1,01 & 4,01 & 0,64 & 7,46 & 0,41 & 7,30 & 0,41 \\
2 butanona & 14,27 & 0,03 & 11,95 & 0,78 & 20,82 & 0,31 & 16,55 & 0,12 \\
2-metil butanal & 6,21 & 0,66 & 4,01 & 0,01 & 4,71 & 0,04 & 5,73 & 0,16 \\
3-metil butanal & 3,70 & 0,38 & 2,06 & 0,06 & 2,99 & 0,01 & 4,10 & 0,13 \\
Etanol & 3,99 & 0,19 & 1,94 & 0,03 & 3,06 & 0,03 & 2,78 & 0,05 \\
2,5-dimetil furano & 1,34 & 0,12 & 0,975 & 0,175 & 1,24 & 0,05 & 1,33 & 0,24 \\
2,3 butanodiona & 5,31 & 0,25 & 3,57 & 0,52 & 6,24 & 0,09 & 4,24 & 0,27 \\
2,3 pentanodiona & 7,14 & 0,53 & 6,00 & 0,67 & 7,21 & 0,30 & 5,25 & 0,06 \\
Piridina & 58,71 & 1,81 & 57,24 & 0,04 & 77,34 & 1,78 & 71,46 & 1,99 \\
Pirazina & 5,00 & 0,10 & 4,15 & 0,47 & 6,30 & 0,10 & 8,01 & 0,03 \\
\hline
\end{tabular}

${ }^{a}$ DP - Desvio Padrão

A variação na concentração dos voláteis em cada pó é devida a diferentes procedências e misturas dos grãos usados nas torrefações e dos diferentes graus de torração que, influenciam nas reações químicas que ocorrem durante este processo, responsáveis pela formação dos compostos aromáticos. A soma das concentrações das espécies que formam aromas na Tabela 2 do café A1 foi $139,29 \mathrm{mg} / \mathrm{kg}$; do café A2 111,20mg/kg; do café $B 173,28 \mathrm{mg} / \mathrm{kg}$; do café C 150,63mg/kg. Estes dados não são absolutos, uma vez que a tabela não apresenta todos os aromas, mas podem ser usados de forma comparativa entre os pós. Valores absolutos podem ser obtidos dos cromatogramas de origem, através das áreas totais dos "picos", como indicado na Tabela 3 .

TABELA 3. Áreas totais dos picos dos cromatogramas dos pós de café

\begin{tabular}{cc}
\hline Café & Área total dos picos (pA.s) \\
\hline A1 & 2363 \\
A2 & 2125 \\
B & 2925 \\
C & 2420 \\
\hline
\end{tabular}

Diferenças podem ser, também, resultado do tratamento dado ao pó no período posterior à torração e que precede o embalamento. A cada hora que o café torrado é deixado no ambiente aberto, perdas de aromas ocorrem [13]. Podem se passar várias horas até que as sementes torradas sejam moídas, para então serem embaladas, sendo que algumas empresas deixam as sementes torradas expostas por uma noite até serem processadas no dia seguinte. Este procedimento é empregado para a eliminação do $\mathrm{CO}_{2}$ formado durante a torração, porém requer ambientes especiais com umidade controlada, o que raramente ocorre no Brasil. Como o produto é altamente higroscópico, ele absorve água rapidamente, o que acelera as reações de oxidação dos aromas.

Observamos que a embalagem convencional do café apresentou uma maior concentração de aromas que a embalagem a vácuo. Como se trata do mesmo pó, isto pode ser explicado porque, durante o processo de retirada do ar do interior da embalagem a vácuo, parte dos voláteis são também removidos, fazendo com que o café embalado a vácuo seja menos aromático que os de embalagens convencionais no período imediatamente posterior ao seu embalamento.

Dentre os componentes presentes em maior concentração, a acetona (2-propanona) e a 2-butanona têm contribuição sensorial menos evidente ao aroma de café [6]. Piridina, que é o composto mais concentrado em todos os pós, apresenta um odor individual descrito como irritante e amargo e pode contribuir para a formação do aroma de café envelhecido (3).

$O$ café $\mathrm{C}$ tem torração extra-forte e apresentou quantidades iniciais de 2,3 butanodiona e 2,3 pentanodiona menores que os cafés A (embalagem almofada) e C. Estas observações estão de acordo com HOLSCHER e STEINHART [6], que reportaram uma pequena queda na concentração desses compostos com o aumento do grau de torração de café.

\section{4 - CONCLUSÕES}

Os experimentos permitem observar que o presente método é uma técnica simples e uma boa ferramenta na análise de aroma de café, possibilitando a análise quantitativa dos voláteis presentes em maior concentração, sem interferências decorrentes de outras técnicas, tais como destilação ou concentração em polímeros porosos. O amostrador automático de "headspace" possibilita que as amostras sejam aquecidas e injetadas de maneira uniforme, possibilitando boa repetibilidade dos resultados e eliminando a necessidade de um grande número de injeções de uma mesma amostra.

Alguns componentes do aroma de café que a literatura reporta como importantes e que poderiam estar presentes em concentrações detectáveis por este método, não foram encontrados, o que reforça a importância das influências regionais e de processamento na qualidade do café.

Uma aplicação prática do método pode ser a caracterização dos voláteis de diferentes pós de café quanto a sua variedade, origem e condições de processamento, procurando estabelecer parâmetros de qualidade regionais, que possam ser correlacionados estatisticamente, de forma análoga a estudos anteriores efetuados com cafés de diferentes países [8, 9, 16].

Outra aplicação é o acompanhamento da concentração dos voláteis de pós em diferentes embalagens comerciais, durante a vida-de-prateleira do produto, estabelecendo critérios de qualidade das embalagens em relação aos pós. 


\section{5 - REFERÊNCIAS BIBLIOGRÁFICAS}

[1] BÁRTHOLO, G.F.; GUIMARÃES, P.T.G. Cuidados na colheita e preparo do café, EPAMIG - Informe Agropecuário v.18, n. 187, p. 33-42, 1997.

[2] BLANK, I.; SEM, A.; GROSH, W. Potent odorants of the roasted powder and brew of Arabica coffee Zeitschrift für Lebensmittel-Untersuchung und Forschung v. 195, p. 239-245, 1992.

[3] CARVALHO, V. D.; CHAGAS, S.J.R.; SOUZA, S.M.C. Fatores que afetam a qualidade do café EPAMIG - Informe Agropecuário v. 18, n. 187, p. 5-20, 1997.

[4] FLAMENT, I. Coffee, cocoa and tea Food Reviews International v. 5, p. 317-414, 1989.

[5] HEWLETT-PACKARD COMPANY HP 7694E Headspace Sampler Operating and Service Manual Little Falls Analytical Division, Wilmington, 120pp., 1996.

[6] HOLSCHER, W.; STEINHART, H. Investigation of roasted coffee freshness with an improved headspace technique Zeischift für Lebensmittel Untersuchung und Forschung v. 195, p. 33-38, 1992.

[7] HOLSCHER, W.; VITZTHUM, O. G.; STEINHART, H. Identification and sensorial evaluation of aroma-impact coumpounds in roasted colombian coffee Café Cacao Thé v. 34, n. 3, p. 205-212, 1990.

[8] LIARDON, R.; OTT, U. Application of multivariate statistics for the classification of coffee headspace profiles Lebensmittel Wissenchaft und Technology v. 17, p. 32-38, 1984.

[9] MUROTA A. Canonical discriminant analysis applied to headspace GC profiles of coffee cultivars, Bioscience,
Biotechnology, Biochemistry v. 57, n.7, p. 1043-1048, 1993.

[10] RAMOS W. O mercado interno e a qualidade do café (entrevista) EPAMIG - Informe Agropecuário v.18, n. 187, p. 73-76, 1997.

[11] SEMMELROCH, P.; GROSCH, W. Analysis of roasted coffee powders and brews by gas chromatography-olfactometry of headspace samples, Lebensmittel Wissenchaft und Technology v. 28, p. 310-313, 1995.

[12] SHIMODA, M.; SHIBAMOTO, T. Isolation and identification of headspace volatiles from brewed coffee with na on-column GC/MS method, Journal of Agriculture and Food Chemistry v. 38, p. 802-804, 1990.

[13] SIVETZ M.; DEROSIER, N.W. Coffee technology The AVI Publishing Co., Westport. p. 347-307,1979.

[14] TASSAN, C.G.; RUSSEL, F. Sensory and gas chromatographic profiles of coffee beverage headspace volatiles entrained on porous polymers, Journal of Food Science v. 39, p. 64-68, 1974.

[15] TRESSI R., SILWAR R. Investigation of sulfur-containing components in roasted coffee Journal of Agricultural and Food Chemistry v.29, p.1078-1082,1981.

[16] WADA, K.; OHGAMA, S.; SASAKI, H.; SHIMODA, M.; OSAJIMA, Y., Classification of various trade varieties of coffee by coupling of sensory data and multivariate analysis Agriculture and Biology Chemistry v.51, p. 1745-1752, 1987.

\section{6 - AGRADECIMENTOS}

Os autores agradecem à FAPESP - Fundação de Amparo à Pesquisa do Estado de São Paulo pelo suporte financeiro. 